\section{G126 ZERO TOLERANCE MULTIDISCIPLINARY APPROACH CAN MINIMISE MEDICATION ERRORS IN PAEDIATRICS}

doi:10.1136/archdischild-2013-304107.138

PV Dissanayake, R Jayatunga, A Ahmed. Paediatrics, Sandwell and West Birmingham Hospitals NHS Trust, West Bromwich, UK

Introduction Children are at increased risk of medication errors due to factors such as body weight, composition, age and organ immaturity and also being unable to challenge or take ownership. Despite standards being set on safe prescribing (BNF \& Trust Prescribing Policy, 2007), errors are frequent during prescribing, dispensing and administration of medications as shown by the EQUIP study (2009).

Method In a secondary-care setting, each medication error was reported as a clinical incident via Trust Incident Reporting System and was graded (green, yellow, amber and red) according to the risk matrix. Baseline data was collected prospectively of all medication errors from $1^{\text {st }}$ January to $30^{\text {th }}$ September 2011, and compared with data for the same period in 2012. A zero-tolerance policy to drug errors was introduced in October 2011 by setting up a Multidisciplinary Medication Safety Group which implemented changes which included, increasing the awareness of medication safety amongst all groups of members of staff who received targeted training in prescribing, dispensing and administration. Irrespective of the severity of the incident, table-top reviews were convened and members of staff were requested to reflect upon their practise. (Details will be discussed).

Results Baseline medication errors of 49(in 2011) decreased to 20(in 2012) following the intervention despite a 30\% increase in the incidence of overall incident reporting in 2012. Statistics (paired T-test) was highly significant $(\mathrm{p}<0.0001)$.

\section{Abstract G126 Table 1}

\begin{tabular}{llll}
\hline & Other incidents & Medication errors & Total incidents \\
\hline Before intervention & 7733 & 49 & 7782 \\
After intervention & 10588 & $20($ expected -67$)$ & 10608 \\
\hline
\end{tabular}

There were no red medication errors in either year, and the amber category improved best.(by $76 \%$ ). Inpatient wards had high volume of errors ( $69 \%$ and $65 \%$ ) but also the best improvement (by $62 \%$ ). Conclusion It is possible to reduce medication errors by a zerotolerance approach, with changes implemented through a multidisciplinary team. We are committed to ensuring patient safety in this high risk high volume area by continued monitoring. This is an example of upholding the Hippocrates Oath; primum non nocere, as we demonstrated the ability of minimising iatrogenic harm by instituting good medical practise.

\section{G127 THE CAR SEAT CHALLENGE - 18 MONTHS EXPERIENCE IN A DGH}

doi:10.1136/archdischild-2013-304107.139

R Towler, R Eastwood, B Ballantyne, R Arya. Paediatrics, Great Western Hospital NHS Foundation Trust, Swindon, UK

Aims The American Academy of Paediatrics recommends the car
seat challenge (CSC) is performed when discharging babies of
$<37$ weeks from neonatal units as they are at risk of apnoeas,
bradycardias and desaturations when seated in infant car safety
seats. This test is not routine in many units however we have been
performing the challenge for the last few years in our hospital. We
present the results of 18 -months experience carrying out the
challenge. Methods Babies $<2.5 \mathrm{~kg}$ or $<37$ weeks gestation on discharge, or with underlying respiratory or neuromuscular problems undergo a
CSC pre-discharge. Baseline observations are monitored lying flat in a cot (30-min) then seated in their car seat (60-min). Desaturation, bradycardias, apnoeas, sleep state, colour and respiratory effort are noted. Babies who fail are re-challenged after repositioning or treatment of the underlying problem.

Results Results of 181 babies challenged over 18-months were retrospectively analysed for various variables including sex, and gestational age and weight at birth and testing. 4/181 (2.2\%) failed the initial challenge and a further three (total $3.8 \%$ ) only passed after removal of a chair cushion. All failures were male, birth-weight 1731-4202 g, gestation 31-40 weeks; age at testing 35-45 weeks; weight $2182-5045 \mathrm{~g}$ and tested in 2009. One was on anti-reflux medication and another had a neuromuscular problem. All 4 babies passed after repositioning. Six babies discharged on home oxygen, and 13 on anti-reflux medication passed first time.

Conclusion The CSC, although time consuming, is well received by parents. Only a few babies failed initially. In our experience, it is useful in identifying babies who may have problems when in an upright position, allowing treatment prior to discharge. There were no failures in 2010 possibly due to more expertise in positioning babies in the seats. However further research into the significance of these events is needed.

\section{G128 DELIVERING BASIC NEWBORN LIFE SUPPORT IN ETHIOPIA: EXPERIENCE FROM THE RCPCH VSO FELLOWSHIP}

doi:10.1136/archdischild-2013-304107.140

1J Laycock, ${ }^{2}$ S Davies-Jones. 'General Paediatrics, Royal Hospital for Sick Children, Edinburgh, UK; ${ }^{2}$ Faculty of Health Sciences, VSO Ethiopia, Harar, Ethiopia

Aims The aim of the project was to ensure that local staff working in labour and delivery wards had the skills and knowledge necessary to recognise and manage a newborn infant in need of resuscitation at birth, in line with international guidelines.

Methods The clinical condition of infants presenting to the neonatal unit and direct observation of practise in the labour ward indicated that the basic steps of newborn life support were not performed in most infants requiring resuscitation thus identifying the need for further training. The local university and Regional Health Bureau assisted us to identify the main centres where babies were delivered, and invite staff from each centre to attend a 2 day basic newborn life support (NLS) training course. The course material developed was based on WHO/Ethiopian national guidelines, and local resources. Funding and equipment were donated by Voluntary Service Overseas (VSO) and UNICEF Ethiopia.

Candidates who performed well during the first course were given further training in facilitation and invited back to instruct on subsequent courses, thereby ensuring that the training is sustainable. The effectiveness of the training was assessed by pre and post course tests, candidate feedback and follow up visits to the sites where participants were practising

Results Four 2 day basic NLS courses were delivered to 80 local nurses, midwives and health officers. 12 local staff attended training in facilitation methods and helped deliver courses 2-4. At the request of the university, 60 final year medical students were also trained, with plans to deliver training to nursing, midwifery and health officer students.

$95 \%$ of candidates showed an improvement in scores in the post course test, and $100 \%$ of the course evaluations indicated the candidate had benefited from training.

On follow up visits, all the sites had set up a newborn corner for resuscitation and had NLS posters provided at the courses displayed appropriately.

Babies referred to the neonatal unit had been more appropriately managed and were accompanied by better documentation.

Conclusion Basic NLS training is a simple effective intervention which can help improve standards of care in a low resource setting. 